better by rest and worse by exercise, and that they may be acconipanied by siight ferer. They may be sharp or more in the nature of a dull aching pain. We cannot possibly maintain that all muscular pains in children are truly sheumatic. Delicate nervous children with intestinal toxacinia, acidosis, and vasomotor disturbances get similar pains, and therefore in diagnosis the whole picture of the 'hild has to be taken into consideration. Pains in the arms, wrists, and fingers are usually rheumatic; and the saise may be said of stiff neck, in the absence of enlarged glands.

In this group with sore throats and pains a certain number of children will develop serious rheumatism, usually arthritis and heart disease, with perhaps nodules. The association between tonsillitis and chorea is less close than that between tonsillitis and arthritis.

\section{The Nervous Group.}

Rheumatism is a nerve poison. When it damages the hrain with sufficient severity, by toxacmia or infection, we get the syndrome which we know as chorea; but long before this condition is reached there is clinical evidence that tho nervous system is affected in rheumatism. No child with any degree of rheumatism fails to show some srmptoms referable to the brain; there is much truth in the saving attributed to a physician of the last generation that "all rheumatic children have chorea; only some more so." For this condition I suggested many years ago the term " latent chorea."

The fundamental change which occurs is that of general nervous instability. The child becomes sharpened up; it is cuick, responsive, excitahle, emotional, and easily depressed or excited. It smiles at you readily and its hands are rather fidgety. These attributes make it rery friendly and explain why the rheumatic children are so popular in hospital.: They also explain why such children do so badly at convalescent homes.

kingrafted on this gencral nervous instability of rheumatic origin may be other disorders which we usually class as functional-sleeplessness, sleep-walking, night terrors, nocturnal enuresis, tics, and so on; and the point which I wish to make is that a certain number of rheumatic children will come first under observation on account of such disorders; or, put the other way round, a proportion of rases secking treatment for various functional nerrous disorders will be instances of rheumatic infection.

The association between rheumatism and general nerrousness. is well recognized. I used to be taught that nerrous children were particularly prone to rheumatism. I am sure this is the wrong way round: a child does not become rheumatic because it is nervous, it becomes nervous because it is rheumatic. There are, of course, many children who conform to this group who are not rheumatic; nevertheless it is out of this group that many cases of rheumatie infection, chiefly chorea, will develop.

\section{The Cardiac Group.}

I come now to the consideration of those signs in a heart which make one suspect rheumatic infection. Sometimes, as we all know, in an individual case the condition of the heart is the one and only diagnostic proof of rheumatism. More often we search the heart for signs of rheumatism to confirm a suspicion of the presence of the disease. In examining the heart of a child for such evidence it is absolutely essential that the examinations should be made when the patient is lying down as well as when he is standing up. Frequently, too, it is well to auscultate the heart with the child lying on its left side.

The signs suspicious of rheumatic heart disease, starting with the least important, are as follows: (1) Increased pulse rate. This is of no diagnostic value unless accompanied by (2) dilatation of the left ventricle-that is, the apex is outside the nipple line. Such a condition probably means the presence of myocarditis, and is therefore suspicious of rheumatism. (3) If with enlargement of the left rentricle there is an apical systolic murmur, audible in any of the postures already mentioned and clearly not a cardio-respiratory bruit, the diagnosis of rheumatism is practically certain. (4) The presence of a reduplicated apical second sound, or of a mid-diastolic apical murmur, is also good evidence of rhemmatism. This "third sound," as it is called, requires careful listening for; it is audible over a very small area intcrnal to the apex beat, and is usually more clearly heard when the child is lying down than when it is standing.

In addition to these changes, which are the ordinary ones found in early rheumatic heart disease, there are certain cases of rheumatism which present themselves as examples of persistent tachycardia. In such instances it may be rery difficult to distinguish the neurotic from tho toxaemic group, and it is therefore woll to remember that certain of the cases of persistent tachycardia met in children will ultimately be found to be of rbeumatic origin.

\section{Summary.}

Now I have been through most of the carly signs and symptoms of rheumatic infection in a child. It will he seen that they are very various, and for the most part slight and rather indefinite. It is this that makes the diagnosis of early rheumatism difficult. It can only be reached by the due consideration of all the signs and symptoms. Where there are several such, cven though each one separately is no more than suspicions, a positive diagnosis may be reached with some certainty. For my own part I think the diagnosis is most easily reached in two stages: first, by a consideration of the general appearance and deportment of the child, of ten enough very characteristic to one familiar with rheumatic children; secondly, by a detailed consideration of the various signs and symptoms, including a careful examination of the heart.

\section{RADIUM TELETHERAPY.}

Note on the Apparates at Present in Use at the Westminster Hospital with Four Grams of Raditm.*

BY

FRANCIS ROCK CARITNG, B.Sc.TOND.,

TECINICAL ADVISER FOR RADIUM WORK, WESTMINSTER HOSPITAL.

The apparatus to be describer was designed at the Westminster Hospital to meet the problem of making the most effective though economical use of the 4 grams of national radium that had been lent to the hospital for use as a " bomb," and, at the same time, of protecting from the emanations all persons except those actually under treatment.

The difficulties of affording proper protection were much simplified by housing the bomb in one of the theatres, which happens to be so situated that below it is a stairway, while above there is an open space, and on each side are two main walls and an area that must be traversed before reaching the wards. It was then anticipated that, by limiting the radiation to an approximately vertical direction, complete safety would be assured. Subsequent investigation by the usual electroscope method showed that the amount of radiation that could be received from the bomb by anyone in the hospital, other than those attending in the bomb room, had no biological significance.

The apparatus is constructed so that two patients may be treated simultaneously, one above and one beneath the radium container (Fig. 1). The lower stretcher is placed ais close to the ground as is convenient in order that the upper stretcher shall not be so high as to offer great difficulty of access. Wach stretcher can be raised, lowered, and traversed longitudinally and laterally, and the lower stretcher can be tilted as well. The stretchers run on wheels, and can easily be moved to and from the bomb.

The radium is held in twenty containers arranged in four groups of five; each group can be withdrawn from use, if required, by pulling the appropriate knob provided outside the bomb (Fig. 2). When not required the radium is all withdrawn so that it is buried in lead. The average protection provided, whether the radium is in use or withdrawn, amounts to some six inches of lead in the horizontal plane, and, when withdrawn, to three inches on the neutral axis. When the apparatus is in use the radium sources are 


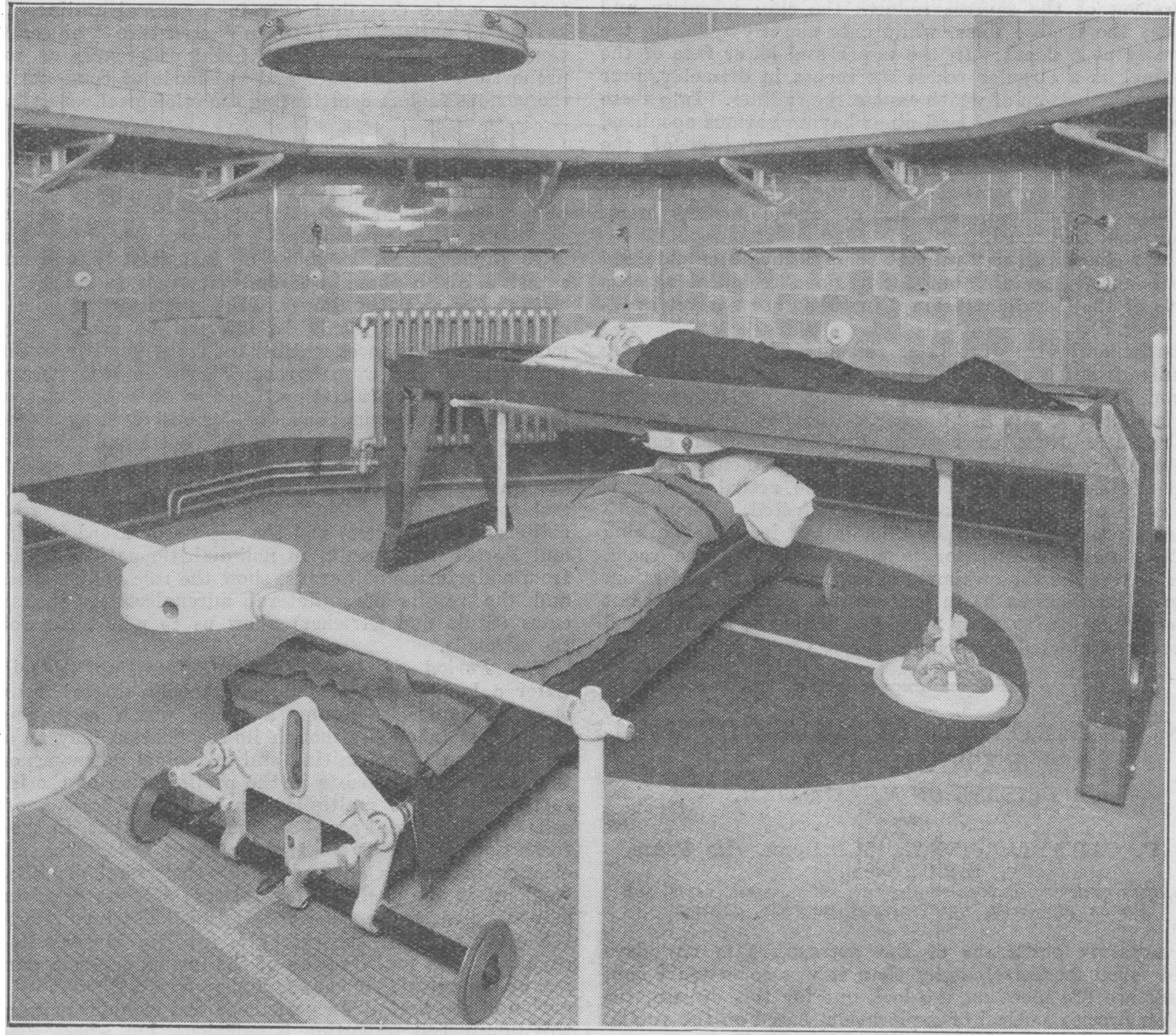

Fig. 1.-The apparatus in use.

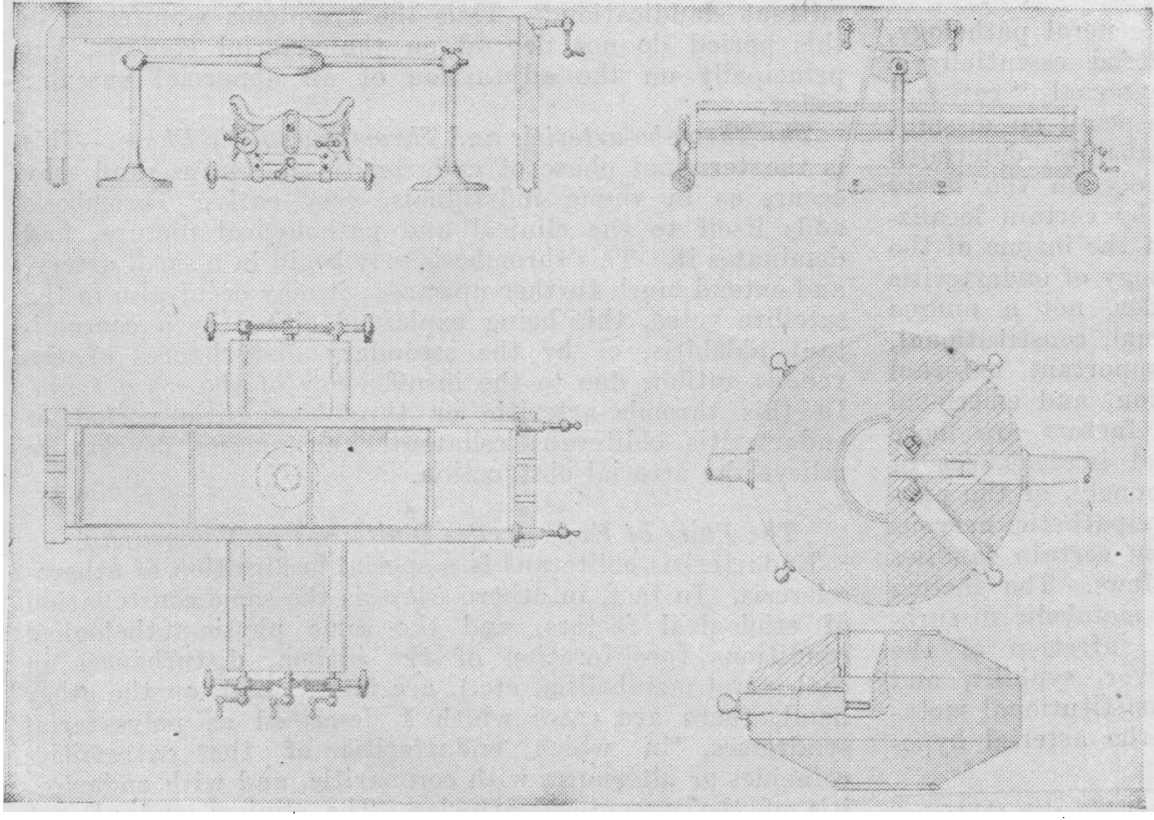

Fig. 2.-Side and end elevation, and plan of apparatus. Detail of container.'

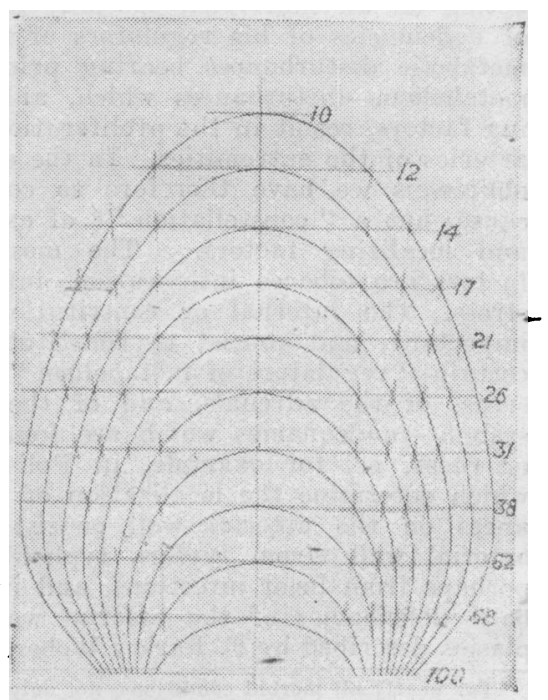

Fig. 3.- Iro-intensity curves in air on a diagonal between two sources. 
approximately at the corners of a four-inch square. The separation of the sources reduces the skin intensity and fiattens the isodose lines, while only slightly reducing the intensity at a depth. In the upper and lower face of the container is a circular recess six inches in diameter, four holes in the bottom of which expose the radium. Into these reresses can be inserted lead plugs having various openings, which to some extent control the dimensions of the "radiant beam." The bomb can be tilted about one axis. The screenage, amounting to the equivalent of just over $1 \mathrm{~mm}$. of platinum, consists of monel metal, brass, aluminium, and wood.

So far charts of the "radiant beam" have bcen obtained experimentally in air, but. for various technical reasons charts of the "radiant beam" in tissue are not yet available (Fig. 3).

The general procedure is as follows: The radium being withdrawn and the stretchers at the end of the room most distant from the "bomb," the pationts are placed in position and moved to the "dummy," which is on the way to the ratium. Here an idea of the best position can be olstained by inspection. The stretcher is then mored on until the same relative position at the actual radium is obtained, and close adjustment is offected. When both patients are adjusted the radium is put into the working position and the operator immediately leaves the room. Thus he receives the minimum of exposiure to the radiation. A nurse who has to be in the rom during the treatment places herself as far away from the radium as possible, and is further protected by a lead shield.

\section{ENDARTERITIS OBLITERANS OF THE EXTREMITIES.}

A DISELSE OF MET.1BOLISII.

$\mathrm{BY}$

\section{A. P. CAWhdis, O.B.E., M.D.Durh. and Paris,} M.R.C.P.LOND.

FOP MERLY CHUEF OF MEDICAL CLINIC, BEAUJON IOSPITAL, PARIS, AND SENIOR PHYSICIAN, EVANGELISMOS HOSPITAL, ATHENS.

ExDintfritis obliterans of the extremities is nowadays found much more frequently than it was some rears ago, because we are more on the look out for this disease, for which a precise method of exploration, based on the oscillometric examination, has been introduced. The frequency of the occurrence of this morbid condition raises important problems as to its plissio-pathology and its treatment.

\section{Etiology.}

Following the modern conceptions of general pathology, cudarteritis obliterans must be considered cssentially a discase of metabolism. A series of cxternal "causes," acting on an individual spccially predisposed on account of deficiencies of his regulators of motabsolism, determine metabolic disturbances bearing principally on the lipoid metabolism-disturbances which, aided by certain localizing factors, result in the proliferation of the intima of the arteries of the extremities. In the etiology of endarteritis obliterans we have therefore to consider, not a unique cause, but a " constellation" and localizing factors. The most important external factors are tobacco intoxication, infection, and emotional stress. The internal or constitutional factors are more important, and consist in constitutional inadequacies of crtain "regulators of metabolism"-namely, of the pancreas, of the adrenals, and of the srmpathetic nerrous system-inadequacies which are found in certain fanilies or races, as, for example, in Polish Jews. The factors which determine the localization of the metabolic disturb ances on the arterial wall consist in infection of the arterial wall (from typhus, typhoid ferer, syphilis, and perhaps from focal infection), and in constitutional metabolic deficiencies of the arterial wall, the arterial hypoplasias described by F. Parkes Weber.

* For nearly all morbil conditions, not only for endarteritis obliterans, we no longer look for "one cause," but for multiple etiological conditions-that is, for a constellation of etiological factors, to use the
It must be realized that the constellation of etiological factors can be described only in a gencral outline. Wach individual patient has his own "structure" of constellation-that is, there are individual differences as to the proportionate importance and the mode of combination of the rarious factor's constituting the ctiological constellation.

\section{Physio-pathological and Clinical Evolution of} Endarteritis Obliterans.

Three phases or periods must be distinguished in the physio-pathological and clinical evolution of endarteriti obliterans of the extremities-a pre-arteritic plase of metabolic disturbances, a phase of incompletely obliterating arteritis, and a phase of thrombo-arteritis.

The Pre-arteritic Phase.-The features of the prearteritic phase can only be inferred by considering the metabolic disturbances which have been found in confirmed endarteritis, and which probably prccede for many years the endarteritic localization. These disturbances bear' on the lipoid metabolism, as can be demonstrated by the occurrence of hypercholesterinaemia (J. Heit\%) and the presence of cholesterol deposits in the endarteritic lesions. They are due to disturbed function of the pancreas, adrenals and sympathetic srstem. The frequency of endarteritis obliterans in diabetes, and the results obtained by Vaquez and Yacoel with insulin in non-diabetic patients suffering from endarteritis obliterans, show the role of the pancreas, and the results of unilateral adrenalectomy in certilin cases (Stulz and Stricker) allow us to admit the role of the adrenals.

The Period of Incompletely Obliterating Arteritis.After a long period of purely metabolic disturbances the endarteritic lesion occur's, a lesion which is principally trophic-metabolic-although its localization may be aided by infection. The initial and principal phenomenon in this endarteritis consists in the proliferation of the intima - that is, in the multiplication and stratification of the cells of this arterial coat-and, more than that, in the neoformation of connective tissue rich in colls. The lamina elastica interna is often divided; cholesterol deposits are frequent in the proliferating intima; calcium deposits are more tardive, and much less frequent. The involvement of the other coats of the artery is tardive, inconstant, and atypical. The proliferation of the intima causes a narrowing of the arterial lumen, and therefore a diminished irri. gation of the limbs. Tn periods of rest or quiet movements this diminished irrigation is sufficient, but where there is a greater demand for blood, as in more active movements, the incompletely obliterated artery, instead of dilating as it normally does to increase the circulation, cortracts spiasmodically, and this vascular spasm is felt as pain of "intermittent claudication." Thus the srmptoms manifested in this period do not depend on the arterial stenosis, but principally on the adjunction of an abnormal vascular reflex.

The Thrombo-arteritic and Thrombo-angiitic Phase.-This is the terminal phase of endarteritis obliterans, and may occur, as in roung individuals, rery early. Thrombosis adds itself to the clinical and pat!ological pieture, and dominates it. This thrombosis may begin in a small artery, and extend much further upwards; it may occur also in the satellite reins, this being explained either by a concomitant phlebitis, or by the secondary disturbances of the renous outflow due to the insufficiency of the ris " trrgo, In this thrombo-arteritic or thrombo-angiitic period of endarteritis obliterans collateral anastomoses develop to relieve the arterial obstruction.

The I'lace of Endarteritis Obliterons in Nosography.

Endarteritis obliterans is a special localization of atherosclerosis. In fact, in athero-scleresis the same constellation of etiological factors, and the same phrsio-pathological conditions (proliferation of the intima, disturbances in cholesterol metabolism, etc.), are found; and, on the other hand, there are cases which I described as polyarterial syndromes, in which endarteritis of the extremities coincides or alternates with coronaritis, and with endarteritis of the mesenteric arteries. The clinical and physiopathological history of endarteritis obliterans is identical with that of the other lncalizations of athero-sclerosis. In 